\title{
Application of poly(3,4-ethylenedioxythiophene)/manganese Dioxide Composite-Modified Electrode for Sensitive Electrochemical Detection of Luteolin
}

\author{
Yinxiu Zuo ${ }^{1,2, \dagger}$, Jingkun Xu ${ }^{1, \dagger}$, Kaixin Zhang ${ }^{3}$, Xuemin Duan ${ }^{1,}{ }^{*}$, Limin $\mathrm{Lu}^{2,{ }^{*}}$, Liping Wu ${ }^{1}$, Guo Ye ${ }^{1}$, \\ Youshan Zhang ${ }^{1}$, Huakun Xing ${ }^{1}$, Liqi Dong ${ }^{1}$, Hui Sun ${ }^{1}$, Xiaofei Zhu ${ }^{1}$ \\ ${ }^{1}$ Shool of Pharmacy, Jiangxi Science and Technology Normal University, Nanchang 330013, PR \\ China \\ ${ }^{2}$ College of Science, Jiangxi Agricultural University, Nanchang 330045, PR China \\ ${ }^{3}$ Centre for Nanoscale BioPhotonics, Macquarie University, North Ryde, 2109, NSW,Australia \\ $\uparrow$ These authors contributed equally to this work and should be considered co-first authors. \\ *E-mail: duanxuemin@126.com(X. Duan), lulimin816@hotmail.com(L. Lu)
}

doi: $10.20964 / 110378$

Received: 17 January 2016 / Accepted: 25 February 2016 / Published: 1 April 2016

In this work, the electrochemical determination of luteolin using poly(3,4ethylenedioxythiophene)/manganese dioxide nanocomposite modified glassy carbon electrode (PEDOT/ $\mathrm{MnO}_{2} / \mathrm{GCE}$ ) is reported. PEDOT/ $\mathrm{MnO}_{2}$ nanocomposite has been proposed via a simple twostep deposition approach. Electrochemical results revealed that PEDOT/MnO $\mathrm{M}_{2}$ showed enhanced electrocatalytic performance toward luteolin, which might be attributed to good conductivity and accelerated electron transfer of PEDOT and good catalytic effect of $\mathrm{MnO}_{2}$. Experimental conditions, including $\mathrm{pH}$ values and scan rates were optimized. In optimal conditions, a good linear relationship was found between oxidation peak currents and the concentration of luteolin in 5.0 nM-7.0 $\mu \mathrm{M}$ range. The detection limit was calculated to be $1.8 \mathrm{nM}$ at a signal-to-noise ratio of 3. Finally, the applicability for luteolin determination in real samples was successfully demonstrated.

Keywords: Poly(3,4-ethylenedioxythiophene); Manganese dioxide; Two-step deposition ; Luteolin

\section{$\underline{\text { FULL TEXT }}$}

(C) 2016 The Authors. Published by ESG (www.electrochemsci.org). This article is an open access article distributed under the terms and conditions of the Creative Commons Attribution license (http://creativecommons.org/licenses/by/4.0/). 